\title{
HIGHLIGHTS ON THE EVOLUTION OF THE BALANCED SCORECARD AS A MODEL FOR MANAGING STRATEGY DEVELOPMENT AND CONTROL
}

\author{
Venelin Terziev ${ }^{1}$ and Marin Georgiev ${ }^{2}$ \\ ${ }^{1}$ Professor, Eng., D.Sc. (Economics), D.Sc. (National security), Ph.D., Vasil Levski National Military \\ University - Veliko Tarnovo, Bulgaria, University of Rousse - Rousse, Bulgaria \\ ${ }^{2}$ Ph.D. student, Vasil Levski National Military University - Veliko Tarnovo, Bulgaria
}

\begin{abstract}
This article explores the development of the concept of the balanced scorecard in various conditions. Observing the process of perfecting the idea provides information about the way this concept adapts both to specific organizational needs and industrial specificities. Exactly for this reason, as a focal point of the article could be identified the functional development of the balanced scorecard and its transformation from a model of analysis and assessment to one which could be applied to expressed organization and corporate strategies.
\end{abstract}

Keywords: Balanced scorecard (BSC), model, strategy, concept, perspective, Stakeholder theory

\section{INTRODUCTION}

In recent years, the number of organizations which implement balanced scorecards in their work has been on the increase. Consultants and other specialists agree that a big proportion of the organizations using this method do this by giving it a different name, and at the same time developing their own multi-criteria analysis format (scorecards), partly resembling its original. All these models share one common feature - they allow measuring and controlling such parameters of organisations' work that cannot be adequately reflected by the methods of traditional financial control.

Every new version of the balanced scorecard (BS) demonstrates an attempt to reach more detailed aspects which companies are analysed against in view of acknowledging the interest of a greater number of stakeholders. A significant reason for this is given every time the Stakeholder theory is rethought and adapted. As a result of this, and based on critical analysis of the BS concept and using well-justified arguments, M. Jensen disproves the radical statement that BS's are a management equivalent of the Stakeholder theory (2001) that his team has developed. 


\section{DEVELOPMENT OF THE CONCEPT OF THE BALANCED SCORECARD}

A graphic example for applying this approach is the BS model which was developed and implemented by the Swedish company ABB (see Fig. 1). This was done in 1994 as part of the internal project EVITA (The abbreviation of the term translated from Swedish means 'financial and strategic control'). Having been compared to models from this period, which were developed and implemented mainly by representatives of the Kaplan \& Norton consultancy company, ABB place emphasis on the innovatory activity which differentiates itself from the "Business processes" and "Developing personnel" perspectives (the latter also known as "Human capital" in the classic model). The specificity of this addition creates the necessary conditions for rationalizing and optimizing the assessment system (Stoyanov, 2006). Another significant feature of this model is the possibility for a detailed and critical analysis of the relationship with suppliers.

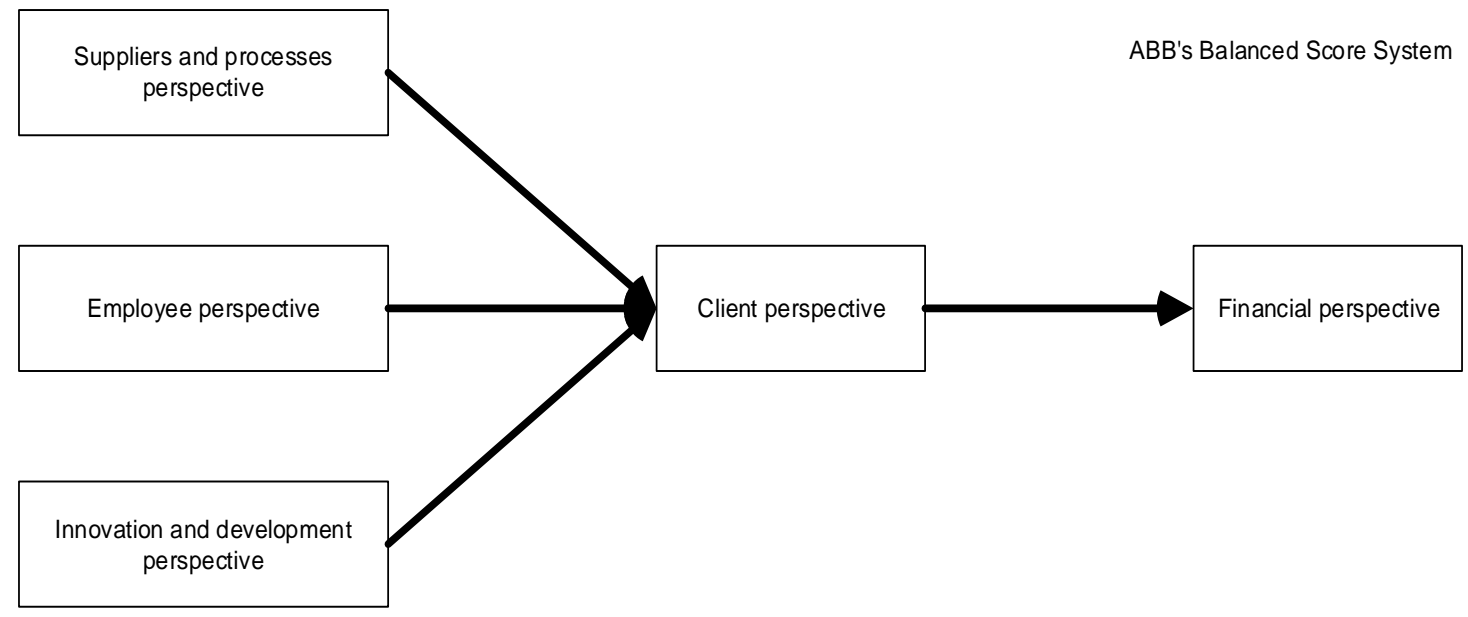

Fig. 1. The ABB's Balanced scorecard model

Source: Neely, A. Measuring Business Performance, 1998, p.188.

The ABB scheme, however, could be criticized for its extreme linearity and lack of explicit reference to feedback for improving knowledge as a part of a closed system with a strategic focus. Every organisation and every type of business possesses characteristics which, combined with their national specificity, contributes to a unique amalgamation defining the specific activity. Taking these factors into consideration when creating strategy leads to a variety of BS's in terms of form and content (Stoyanov, 2009).

An interesting example of a scorecard consolidated through a unique development process can be observed in the work of the British finance and insurance company Halifax. Researching and creating a System for managing current work activity based on the BS method was launched in 1994. Due to a lack of a global strategy and mission, a bottom-up approach was adopted - starting from a department level as opposed to the classic model of Kaplan and Norton (Kaplan \& Norton, 1996). Halifax does not include in its system the training and development and economic growth element. Along with the traditional aspects of the system's content, new ones are included having to do with improving service, corporate culture etc. Over the next four years until 1998, the process acquires a new meaning at organizational level, with all specific aspects of the work as well as the problems related with them being included in a project for creating a common system. Owing to the broad range of activities and services, the process at organizational level lasts for about 9 months.

The concept of the scorecard of the Swedish company "Scandia" presents an interesting example of different functionality and content (Fig. 2). The scorecard project was called "Navigator" because of the fact that the managers of the company regarded it as a management control tool rather than as a strategic scorecard. This project provides a graphic example for a link between an adapted model of a scorecard and developing a concept about intellectual capital (Kaplan \& Norton, 1996; Edvinsson \& Malone 1997). The results of Scandia's project 'Assessment of the intellectual capital' show a shift in the weight of the scorecard in terms of its content, as well as the inclusion in it of a $5^{\text {th }}$ key element of the activity - 'Human resource'. All the other aspects are associated with and accounted for namely by the development of the human capital. It is noteworthy that this project has been worked on for more than 10 years. The model was transformed into one for general control of Scandia in 1999 from a system for internal control of departments. 
The concept of the BSC is a component of a well-developed management and control system focused on a strategic perspective and critical response to traditional management and control. Here one can see the connection between Kaplan and Norton's original assumptions of controlling the BSC with similar assumptions and the idea of the company's intellectual capital (Stoyanov, 2016). In the presence of BSC, financial responsibility and management have been replaced by the richer picture of reality. Not that the monetary criteria have become less important, but also in this connection it is necessary to form a balance in the transition from financial to strategic management of the activity of the organizational activity.

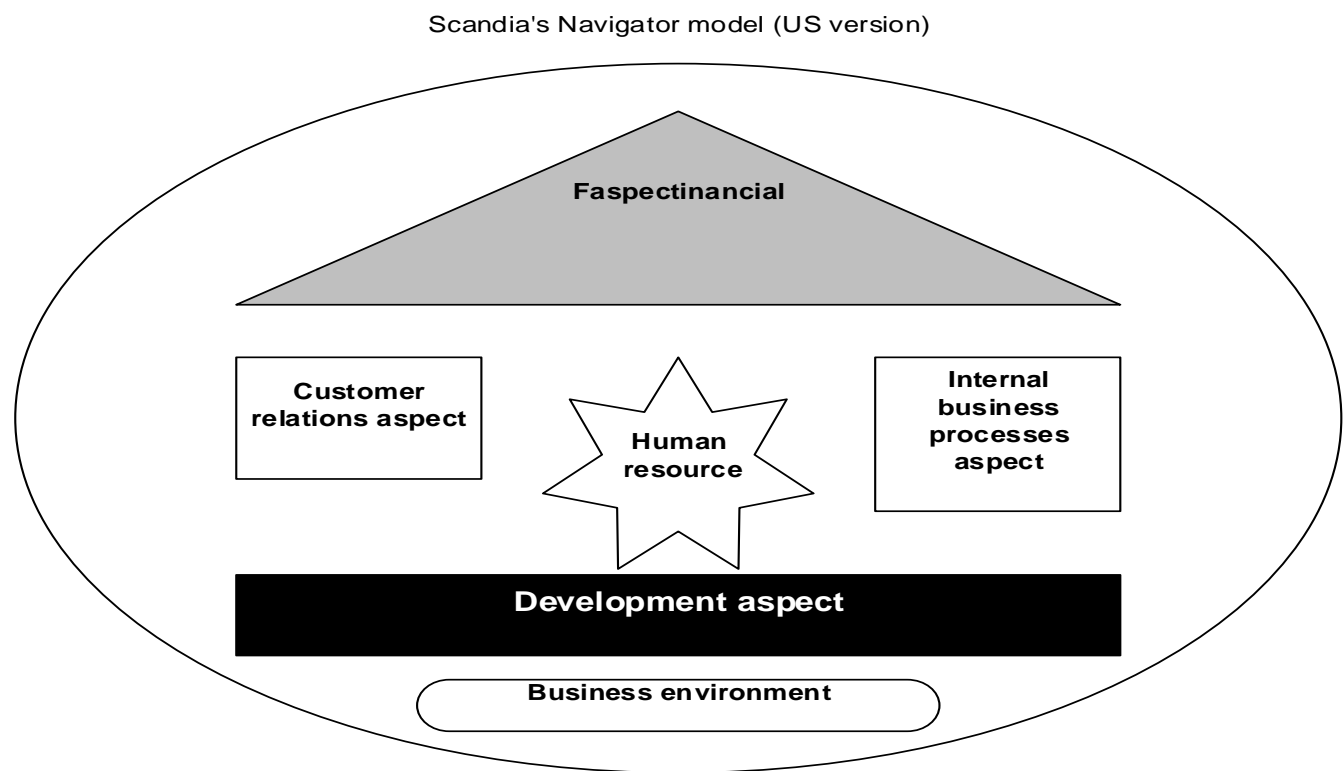

Fig. 2. The Scandia's concept

Source: Olve, N.-G., Roy J., \& Wetter, M. (1999). Performance drivers: a practical guide to using the balanced scorecard, New York: J. Wiley, p. 103.

The company Electrolux has also made a significant contribution to perfecting the concept of developing different aspects of the BS. In carrying out its projects, GIMS (a complex integrated assessment system) and DBM (a system for measuring the dynamics of business), an important dimension can be observed- the relationship between distributor and end consumer in developing the client's prospect. For this reason, two indexes were added to this aspect of the process - one of them for assessing customer satisfaction, the other - distributor satisfaction (Becker et al., 2001). For the reinforcement of these two projects, in 1998 the management of Electrolux implemented internal organizational distribution of information providing every department with regular information regarding projects and regular monitoring of their assessment parameters.

British Airways has also played a significant role in perfecting the BS concept. The ambitious project for implementation of the BS was introduced at the end of 1997. An interesting fact about carrying out the BS project is that the system for planning of the company work makes certain development stages heavier in different respects based on which the initial objectives are transformed.

The system for planning comprises of three aspects - strategic, commercial and production. The strategic one includes long-term planning; the commercial - planning current financial indexes; and the production one - enables the operational planning and monitoring of work. In this respect, the complex objective of the project follows a specific format with strategic stages for a period of three years.

- During year one - the foundations of future development are laid;

- During year two - the departments become competitive in their core field of work;

- During year three - the organisation strengthens its strategic positions.

Important and interesting is the experience which Coca-Cola has had with strategic scorecards. Instead of using the BS model to devise a complex strategy or for control, it patents its own method of implementation. The Coca-Cola Corporation has its unique practice of implementing BSs when opening new branches in every new location. The rationale behind establishing this practice is related, on the one hand, to showing 
trust to co-workers in order for specific goals to be reached or to decentralizing the responsibilities for making decisions. On the other, it is related to decomposing the corporate strategy to an individual level. Linking the work process with a remuneration and incentive system is a new step towards instilling and perfecting a high level of multi-functionality of the Balanced scorecard project.

Another interesting model of scorecard is the one developed by the SKF Company. The main drive for carrying out the BS project is the hope that this new model will replace the classic, traditional budgeting with its numerous flaws, simultaneously keeping merits of it such as defining goals and having control over the implementation of the decisions taken. SKF develops in many ways its own strategic scorecard in comparison with the classic scorecard format.

Although Kaplan and Norton's idea has a significant influence, the SKF concept differs significantly, for example in that strategic and current factors are processed simultaneously. This change results from the fact that while the strategic and current indexes are formed in the algorithm of the project, even the smallest deviation often causes significant damage.

Constantly monitoring the simultaneous update of both types of indexes in terms of content reduces to a minimum any possibilities for deviation. After accumulating experience, conducting critical analysis and observing trends for future development, researchers and consultants summarise the algorithm of development and the content of projects for the implementation of the strategic balanced scorecard. In this respect, a standard is established for how this project takes place, which also allows for it to be considered and used for the needs of strategic control (Stoyanov, 2007).

The first group of problems stems from the fact that proving the cause-effect links on a strategic level by using scientific means is an extremely complex and often impossible task. This results in decision-taking in a situation defined by insufficient information and uncertainty, which is done by the management of the organization (Stoyanov, 2006). The second group of problems is related to the implementation of the balanced scorecards, which comes next. The involving a wider circle of management and leadership members and employees of the organisation, even at the initial stages of the development process of the scorecard, creates better conditions for a better buy-in when it comes to its creation.

\section{CONLCUSION}

The short analysis which was carried out provides evidence which leads to the conclusion that the technology used to develop and implement BSs invariably involves applying the principle of team work. Approaching the work process as a team is regarded as an excellent opportunity for combining an expert approach allowing for scientific methods to be applied, and practical experience where the intuition of different management personnel at different levels of the organisation included. Brainstorming and group discussions done in the process of consecutive iterations are regarded as the main method in developing the scorecards. This allows for a more adequate way of solving two groups of crucial problems taking into account the needs of modern organisations

\section{REFERENCES LIST}

Becker, B., Huselid, A., \& Ulrich, D. (2001). The HR-scorecard: linking people, strategy and performance, HBR Press, Boston.

Edvinsson, L., \& Malone, M.S. (1997). Intellectual Capital: Realizing Your Company's True Value by Finding Its Hidden Brainpower.

Jensen, M. (2001). Value maximization, stakeholder theory, and the corporate objective function, Journal of applied corporate finance.

Kaplan, R., \& Norton, D. (1996). The BS: Translating Strategy into Action. Harvard College.

Neely, A. (1998). Measuring Business Performance, 1998.

Olve, N.-G., Roy J., \& Wetter, M. (1999). Performance drivers: a practical guide to using the balanced scorecard, New York: J. Wiley.

Stoyanov, E. (2006). Alternatives in strategic control and sustainable development. Management and sustainable development 1-2, 356-359. 
Stoyanov, E. (2006). Problems in design and use of the Balanced scorecard as an instrument of control. Jubileee scientific conference " 30 years Department of Financial control at the University of national and world economy".

Stoyanov, E. (2007). Characteristics of the Bulgarian issues in work on the Balanced scorecards as an instrument of control. Management and sustainable development 1-2, 271-273.

Stoyanov, E. (2009). Systems of management control. Libra scorp, Burgas.

Stoyanov, E. (2016). Opportunities of modern understandings on human capital. Journal of Economic Development, Environment and People 5-4, 52-57. 